\title{
Prevalence of Hypertension among Patients with Type 2 Diabetes Mellitus and Its Socio Demographic Factors in Nigist Ellen Mohamed Memorial Hospital Hosanna, Southern Ethiopia
}

Kaleab Tadesse ${ }^{1^{*}}$, Hiwot Amare ${ }^{2}$, Tesfahun Hailemariam ${ }^{3^{*}}$ and Tewodros Gebremariam ${ }^{4}$

${ }^{1} 1$ Department of Human Physiology, School of Medicine, College of Medicine and Health Sciences, Wachemo University, Ethiopia ${ }^{2}$ Department of Internal Medicine, College of Medicine and Health Sciences, Jimma University, Ethiopia

${ }^{3}$ Department of Health Informatics, Hawassa College of Health Sciences, Hawassa, Ethiopia

${ }^{4}$ Department of Biomedical Science, College of Medicine and Health Sciences, Jimma University, Ethiopia

\begin{abstract}
Introduction: World Health Organization revealed $13 \%$ of all deaths globally related to hypertension making it an area of prime importance for public health in both developing and developed Country. The problem of hypertension is significant in low and middle income countries like sub-Saharan Africa; however, there are limited studies to report the exact prevalence rate in developing countries, particularly in Ethiopia. Therefore, the aim of this study was to determine prevalence of hypertension among patients with type 2 diabetes mellitus and its socio demographic factors in Nigist Ellen Mohamed Memorial Hospital Hosanna, Southern Ethiopia.
\end{abstract}

Methods: Hospital based cross-sectional study was conducted in 140 randomly selected adult type 2 Diabetes Mellitus patients in Nigist Ellen Mohammed Memorial Hospital, Southern Ethiopia. Data was collected by measuring blood pressure of the study participants by using calibrated devices and interviewer administered questionnaires were used to assess prevalence and socio-demographic factors among the study participants. The collected data were entered, cleared and analyzed by using SPSS 20.0 version.

Result: Mean $( \pm S D)$ age of the clients was $46.5( \pm 11.8)$ years and majority $(63.6 \%)$ was male. The mean $( \pm S D)$ Systolic blood pressure and Diastolic blood pressure of study subjects among type 2 Diabetes Mellitus clients were $135.98( \pm 17.11)$ and $88.89( \pm 12.77) \mathrm{mmHg}$ respectively. More than half $(55 \%)$ of the type 2 diabetic clients in this study were hypertensive. Finally, there is a significant association between age, gender, marital status, residence and average working hours.

Concussion: Prevalence rate of hypertension among type 2 diabetic patients in Hosanna Nigist Ellen Mohammed Memorial Hospital was high. More than half of the study subjects in Nigist Ellen Mohamed Memorial Hospital hospital were hypertensive.

Keywords: Hypertension; Type 2 diabetes mellitus; Prevalence; Multivariable analysis

\section{Abbreviations}

BP: Blood pressure; CVD: Cardiovascular disease; DBP: Diastolic blood pressure; DHTN: Diastolic hypertension; HTN: Hypertension; IDBP: Isolated diastolic blood pressure; IDHTN: Isolated diastolic hhypertension; ISBP: Isolated systolic blood pressure; ISHTN: Isolated ssystolic hypertension; JNC-8: Eighth joint national committee (JNC 8) for prevention, detection, evaluation and treatment of high blood pressure; NCDs: Non communicable diseases; NEMMH: Nigist Ellen Mohammed Memorial Hospital; SBP: Systolic blood pressure; SHTN: Systolic hypertension; T2DM: Type 2 diabetes Mellitus

\section{Introduction}

We live in a rapidly changing environment. One of the most striking examples of this shift is the fact that non communicable diseases such as cardiovascular disease, cancer, diabetes and chronic lung diseases have overtaken infectious diseases as the world's leading cause of mortality. Up to $80 \%$ of people with diabetes will die of cardiovascular disease, especially hypertension (HTN) and stroke since most patients with diabetes develop hypertension. One of the key risk factors for cardiovascular disease is hypertension and it is present in all populations elsewhere in the world [1-3]. Globally, Cardio-vascular diseases (CVDs) accounts for approximately 17 million deaths a year, nearly one third of the total. Of these, complications of HTN account for 9.4 million deaths worldwide every year.

HTN is responsible for at least $45 \%$ of deaths due to heart disease, and $51 \%$ of deaths due to stroke. HTN has been in the past regarded as a disease of affluence or economically higher class society but this has changed drastically in the last two decades with average blood pressure (BP) now higher in Africa than in Europe and USA and the prevalence of HTN is increasing among poor sections of society. It is reported to be the fourth $\left(4^{\text {th }}\right)$ contributor to premature death in developed countries and the seventh in developing countries [4-8].

*Corresponding author: Kaleab Tadesse, Department of Human Physiology, School of Medicine, College of Medicine and Health Sciences, Wachemo University, Ethiopia, Tel: +251929381413; E-mail: kaleabrich@gmail.com

Tesfahun Hailemariam, Department of Health Informatics, Hawassa College of Health Sciences, Hawassa, Ethiopia, E-mail: Tesfahunhailemariam@gmail.com

Received March 08, 2018; Accepted March 21, 2018; Published March 26, 2018

Citation: Tadesse K, Amare H, Hailemariam T, Gebremariam T (2018) Prevalence of Hypertension among Patients with Type 2 Diabetes Mellitus and Its Socio Demographic Factors in Nigist Ellen Mohamed Memorial Hospital Hosanna, Southern Ethiopia. J Diabetes Metab 9: 792. doi: 10.4172/2155-6156.1000792

Copyright: $\odot 2018$ Tadesse $\mathrm{K}$, et al. This is an open-access article distributed under the terms of the Creative Commons Attribution License, which permits unrestricted use, distribution, and reproduction in any medium, provided the original author and source are credited. 
Citation: Tadesse K, Amare H, Hailemariam T, Gebremariam T (2018) Prevalence of Hypertension among Patients with Type 2 Diabetes Mellitus and Its Socio Demographic Factors in Nigist Ellen Mohamed Memorial Hospital Hosanna, Southern Ethiopia. J Diabetes Metab 9: 792. doi: 10.4172/2155-6156.1000792

Page 2 of 7

The proportion of the global burden of disease attributable to HTN has significantly increased from about $4.5 \%$ (nearly1 billion adults) in 2000 , to $7 \%$ in 2010 . This makes HTN the single most important cause of morbidity \& mortality globally and highlights the urgent need of action to address the problem [9].

The number of patients with HTN is likely to grow as the population ages since either isolated systolic hypertension (ISHTN) or combined systolic and diastolic HTN occurs in the majority of persons older than 65 years. It is reported that clinical significance of $\mathrm{BP}$ reading appears age dependent. In adults especially over age of 50 years, $\mathrm{SBP}>140 \mathrm{mmHg}$ predicts mortality regardless of diastolic readings but under the age of 50 , Diastolic blood pressure (DBP) is a better predictor of mortality than systolic readings. If there is a disparity in category between the systolic and diastolic blood pressures, the higher value determines the severity of the HTN [10-14].

Contrary to common misperception, the burden of NonCommunicable diseases (NCDs) is worst in low and middle-income countries where $80 \%$ of all NCDs occur. In sub-Saharan African countries such as Ethiopia, increased urbanization and changing lifestyle have contributed to the rise in NCDs [15].

Globally, estimated total number of adults with HTN in 2000 was 972 million; 333 million in economically developed countries and 639 million in economically developing countries. The number of adults with HTN in 2025 was predicted to increase by about $60 \%$ to a total of 1.56 billion [16]. Mortality is increased 7.2folds when HTN is present in patients with diabetes. In 2009-2012, of USA adults aged 18 years or older with diagnosed diabetes, $71 \%$ had BP $\geq 140 / 90 \mathrm{mmHg}$ or used prescription medications to lower high BP.

Hypertension is a significant and controllable risk factor for many diseases, but many people do not know that she/he has HTN because HTN is largely a symptomless condition. This study, therefore, helps health care professionals and health care system to identify the prevalence rate of HTN among T2DM patients and its socio-demographic factors among the study participants for better management and risk minimization. It helps, health professionals in hosanna NEMM hospital and other stake holders (T2DM clients, community, health care sectors, medical students, health education experts, non-governmental organizations working on non-communicable chronic disease control and prevention, government policy makers) by providing clear information regarding HTN and its socio-demographic factors in type 2 DM clients, to plan different clinical and non-clinical options before it causes serious damage on target organs of clients. This finding also helps as a base line finding to perform further studies in the area of aggressive high BP lowering methods, since it is not yet well explored by prospective cohort study and brought to the attention of policy makers and practitioners in Ethiopia, particularly in Hosanna NEMM hospital. Therefore, the study aimed to assess the prevalence of Hypertension among patients with type 2 diabetes mellitus and its socio demographic factors in Nigist Ellen Mohamed Memorial Hospital Hosanna, Southern Ethiopia.

\section{Methods}

\section{Study setting and study design}

The study was conducted in South Nations Nationalities and Peoples region, Hadiya Zone, Hosanna town, Nigist Ellen Mohammed Memorial hospital. Hadiya Zone comprises 10 Woredas and 329 Kebeles with the total of $1,506,733$ (8.7\% of the SNNPR population). Hosanna is the administrative town and is located $230 \mathrm{Km}$ far from Addis Ababa, capital city of Ethiopia and $194 \mathrm{Km}$ far from Hawassa (regional city).
Nigist Ellen Mohammed Memorial hospital is the district hospital in Hadiya Zone, which gives service for greater than 1.5 million catchment population. It was established in 1984GC, comprising different Wards, Outpatient departments, Clinics, Chronic disease follow up Unit, Pharmacies and other administrative departments [17]. Hospital based cross-sectional study was conducted.

\section{Sample size determination and sampling procedure}

The required sample size for this study was calculated by using single population proportion formula, considering previous prevalence rate of $26.1 \%$ hypertensive-diabetics among type two DM-patients from the research conducted October 2008 to February 2009 in Hawassa town [18].

$$
n=\frac{P(1-P)(Z \alpha / 2)^{2}}{D^{2}}
$$

Where; $\mathrm{n}=$ sample size; $\mathrm{P}=$ an estimate of proportion of outpatients with prescribed anti-DM drugs and revealed as hypertensive patients under the study; $Z=$ the standard normal value at $(1-\alpha) \%$ confidence level and $\alpha$ is mostly $5 \%$ i.e. with $95 \%$ Confidence level; $\mathrm{D}=$ the margin of sample error tolerated. Therefore, using the above formula, at $95 \%$ confidence level and margin of error $5 \%$ and $p=26.1 \%, D=5 \%=0.05$

$$
\begin{aligned}
& n=\frac{P(1-P)(Z \alpha / 2)^{2}}{D^{2}} \\
& n=\frac{(1.96)^{2} \times 0.261(1-0.261)}{(0.05)^{2}} \\
& n=\frac{(1.96)^{2} 0.5(0.739)}{(0.05)^{2}}
\end{aligned}
$$

$\mathrm{n}=296.385$, rounding up $\mathrm{n}=297$

When the study population is less than 10000 , we can employ sample reduction formula and the sample size will be determined as follows. Currently, there are 219 patients who fulfill the inclusion criteria and attending chronic follow up clinic for type two DM treatment in Hosanna Nigist Ellen Hospital. $\mathrm{N}=219$; Therefore the corrected sample size is calculated as: $N_{f}=n /(1+n / N)$, Whereas, $N_{f}$ is sample size to be obtained by correction formula.

$\mathrm{N}_{\mathrm{f}}=297 \div[1+(297 / 219)]=126.052$ (rounding up) =127; by adding $10 \%$ non-respondent rate on $\mathrm{n}_{\text {new, }}$ by rounding up 139.70 , the final sample size obtained were 140 T2DM patients.

The determined sample size was selected by simple random sampling method from the study population. Prior to the performance of randomization, all of adult type 2-DM patient cards were coded from 1 to 219 (one to total number of study population). It was checked for completeness, and incomplete patient charts were registered in a separate note book to be excluded. The coded numbers from 1 to 219 were entered into online research randomizer-version 4.0. The output of computer-based random numbers generated was printed in hard copy containing different sets of options as per the entry instructed. The data was collected from the set of random numbers that didn't include card numbers with incomplete data by cross-checking based on the incomplete data registered in separate note book.

\section{Data quality assurance and analysis}

Data quality was assured through development of assessment 
Citation: Tadesse K, Amare H, Hailemariam T, Gebremariam T (2018) Prevalence of Hypertension among Patients with Type 2 Diabetes Mellitus and Its Socio Demographic Factors in Nigist Ellen Mohamed Memorial Hospital Hosanna, Southern Ethiopia. J Diabetes Metab 9: 792. doi: $10.4172 / 2155-6156.1000792$

Page 3 of 7

tools from scientific journals. Pilot study was conducted on $10 \%$ of the sampling population after randomization has done in order to exclude those piloted subject from this study. Guidelines and protocols for measuring blood pressure were used. Training was given for data collectors by senior physician before data collection took place and the on-going supervision of data collectors were arranged in day to day manner. Repeated measurements of blood pressure undertaken. Collected data were checked for completeness, entered, cleaned and analyzed using SPSS for window version 20.0. To identify prevalence of hypertension and sociodemographic variables, univariate and multivariable analysis was employed.

To determine association between outcome variable and independent variables, logistic regression model was performed. To select potential candidates for the full model at p-value cutoff point $\leq$ 0.25 were considered. Multivariable binary logistic regression analysis with adjusted odd ratio (AOR) was applied to estimate the independent effect of the model and final model fitness was checked using Hosmer and Lemeshow significance test at $p$-value $<0.05$.

\section{Ethical approval}

Ethical clearance was obtained from Jimma University College of Health Sciences Institutional Research Review Board and oral consent from all study participants were obtained before conducting the study. Only code numbers but not names of the study participants were used at any stage of the study.

\section{Results}

The study randomly recruited one hundred forty respondents out of two hundred nineteen study population with $100 \%$ respondent rate. Mean $( \pm$ SD) age of the clients was $46.5( \pm 11.8)$ years and $89(63.6 \%)$ participants were male. Among the respondents, 126(90\%) were married, 71(50.70\%) were urban residents, 35(25\%) were farmers, 41 (29.30\%) were grade 1 to 8 complete, $15 \%$ (21) were first degree \& above graduates. The mean monthly income of the respondents was 2119 Ethiopian Birr and majority (81.4\%) earned greater than 1051 Ethiopian Birr. Average working hours of the $54.30 \%$ respondents' was less than or equal to 8 hours per day (Table 1).

\section{Prevalence of hypertension and result of multivariable analyses for sociodemographic variables}

The mean $( \pm$ SD) SBP and DBP of study subjects among T2DM clients were $135.98 \pm 17.11$ and $88.89 \pm 12.77 \mathrm{mmHg}$ respectively. The prevalence of hypertension according to WHO definition (systolic blood pressure $\geq 140 \mathrm{mmHg}$ and/or diastolic blood pressure $\geq 90 \mathrm{mmHg}$ or taking antihypertensive medication), and JNC- 8 criteria was found to be $55 \%$ (Figure 1). Off which, Isolated systolic HTN (SBP $\geq 140 \mathrm{mmHg}$ and $\mathrm{DBP}<90 \mathrm{mmHg}$ ) were $8.60 \%$ (male $=5 \%$ ) and Isolated diastolic HTN (SBP $<140 \mathrm{mmHg}$ and $\mathrm{DBP} \geq 90 \mathrm{mmHg}$ ) were $12.90 \%$ (male=8.6\%). Out of the hypertensive diabetic, $50 \%$ of them were newly discovered during this study period, $80.7 \%$ and $75 \%$ of the study participants were not achieved target $\mathrm{BP} \leq 130 / 80 \mathrm{mmHg}$ and $\leq 130 / 85 \mathrm{mmHg}$ respectively. From hypertensive respondents younger than 45 years had predominately diastolic hypertension, whereas the majority of the respondents older than 45 years had isolated systolic hypertension. The proportion of respondents with isolated systolic hypertension increased with age (Figures 2 and 3 ). Study subjects who work for $\leq 8$ hours/day were $60 \%$ [AOR=0.394, 95\%CI: $0.178-0.870$ ] less likely to have HTN as compared to subjects who work for $\geq 8 \mathrm{Hrs} /$ day and average working
Table 1: Sociodemographic characteristics of type 2 diabetic mellitus Clients attending Hosanna Nigist Ellen Mohammed Memorial Hospital.

\begin{tabular}{|c|c|c|c|}
\hline Variables & Category & Frequency(n=140) & Percent (100\%) \\
\hline \multirow{4}{*}{ Age } & $25-34$ years & 21 & 15.0 \\
\hline & $35-44$ years & 35 & 25.0 \\
\hline & $45-54$ years & 48 & 34.3 \\
\hline & $\geq 55$ years & 36 & 25.7 \\
\hline \multirow{2}{*}{ Gender } & Female & 51 & 36.4 \\
\hline & Male & 89 & 63.6 \\
\hline \multirow{4}{*}{ Marital status } & Married & 126 & 90.0 \\
\hline & Unmarried & 7 & 5.0 \\
\hline & Divorced & 2 & 1.4 \\
\hline & Widowed & 5 & 3.6 \\
\hline \multirow{2}{*}{ Residence } & Urban & 71 & 50.7 \\
\hline & Rural & 69 & 49.3 \\
\hline \multirow{7}{*}{ Occupation } & Farmer & 35 & 25.0 \\
\hline & Government employee & 30 & 21.4 \\
\hline & Housewife & 30 & 21.4 \\
\hline & Self-employee & 19 & 13.6 \\
\hline & Retired & 9 & 6.4 \\
\hline & Merchant & 7 & 5.0 \\
\hline & Others* & 10 & 7.2 \\
\hline \multirow{4}{*}{$\begin{array}{l}\text { Average Monthly } \\
\text { Income }\end{array}$} & $<350$ Birr & 3 & 2.1 \\
\hline & 351-750 Birr & 12 & 8.6 \\
\hline & 751-1050 Birr & 11 & 7.9 \\
\hline & $>1051$ Birr & 114 & 81.4 \\
\hline \multirow{7}{*}{$\begin{array}{l}\text { Educational } \\
\text { status }\end{array}$} & Illiterate & 34 & 24.3 \\
\hline & Writing and reading & 8 & 5.7 \\
\hline & Grade 1-8 complete & 41 & 29.3 \\
\hline & Grade 9 to 10 complete & 10 & 7.1 \\
\hline & $\begin{array}{l}\text { Grade } 11 \text { to } 12 \\
\text { Complete }\end{array}$ & 12 & 8.6 \\
\hline & $\begin{array}{l}\text { College diploma } \\
\text { graduates }\end{array}$ & 14 & 10.0 \\
\hline & First degree and above & 21 & 15.0 \\
\hline \multirow{2}{*}{$\begin{array}{l}\text { Average working } \\
\text { hours per day }\end{array}$} & $<=8$ & 76 & 54.3 \\
\hline & $>8$ & 64 & 45.7 \\
\hline
\end{tabular}

hour is significantly associated ( $\mathrm{p}$-value $=0.000$ ) with high blood pressure (Table 2).

Out of the total hypertensive cases, $32.9 \%$ ( 46) were stage-I, $15.7 \%($ 22) were stage-II and $6.4 \%$ (9) were stage-III hypertensive (Figure 4 ). Prevalence of HTN among those aged $25-34$ years was $7(5 \%, \mathrm{~N}=140)$, among those aged $35-44$ years was $17(12.14 \%, \mathrm{~N}=140)$, among those aged $45-54$ years was $28(20 \%, \mathrm{~N}=140)$ and $25(17.86 \%, \mathrm{~N}=140)$ among those aged 55 and above (Figure 5). Participants who were in the age group of 35-44 years, $45-54$ years and $\geq 50$ years were 2.3 times $(\mathrm{AOR}=2.287$, 95\% CI: $1.478-10.936), 3$ times (AOR=2.922, 95\%CI: $1.694-12.298)$ and 6.4 times $(\mathrm{AOR}=6.396,95 \% \mathrm{CI}: 1.22-33.496)$ respectively more likely to have HTN as compared to individuals who were at the age group of 25-34 years. Age groups 35-44 years ( $\mathrm{p}$-value=0.022), 45-54 years ( $p$-value $=0.003$ ) and $\geq 55$ years ( $p$-value $=0.000)$ were statistically associated. The prevalence rate of hypertension among female and male subjects was $17.14 \%$ and $37.86 \%$ respectively. Male subjects were 2.708 times $(\mathrm{AOR}=2.708,95 \% \mathrm{CI}: 1.696-4.325)$ more likely to have HTN as compared to female subjects and gender is significantly associated (p-value $=0.000)$ with HTN (Figure 6). Married subjects were 15.17 times (AOR=15.167, 95\%CI: 1.935-246.129) and divorced subjects were 6.9times $(\mathrm{AOR}=6.85,95 \% \mathrm{CI}: 1.821-57.185)$ more likely to have 
Citation: Tadesse K, Amare H, Hailemariam T, Gebremariam T (2018) Prevalence of Hypertension among Patients with Type 2 Diabetes Mellitus and Its Socio Demographic Factors in Nigist Ellen Mohamed Memorial Hospital Hosanna, Southern Ethiopia. J Diabetes Metab 9: 792. doi: $10.4172 / 2155-6156.1000792$

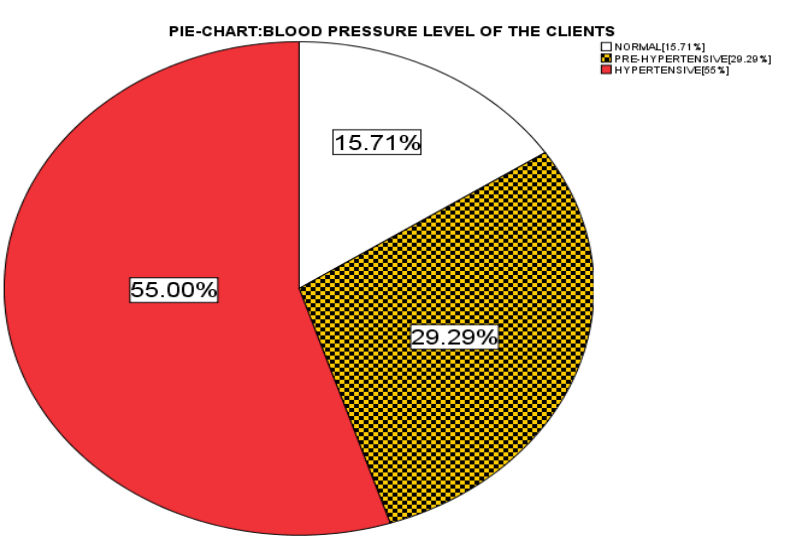

Figure 1: Shows blood pressure level of the study participants at hosanna NEMM hospital.

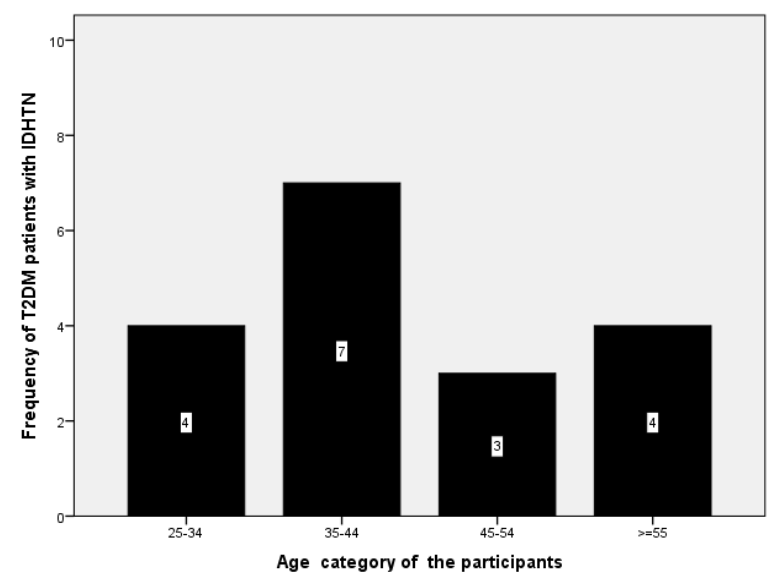

Figure 2: Shows IDHTN of the participants in different age categories.

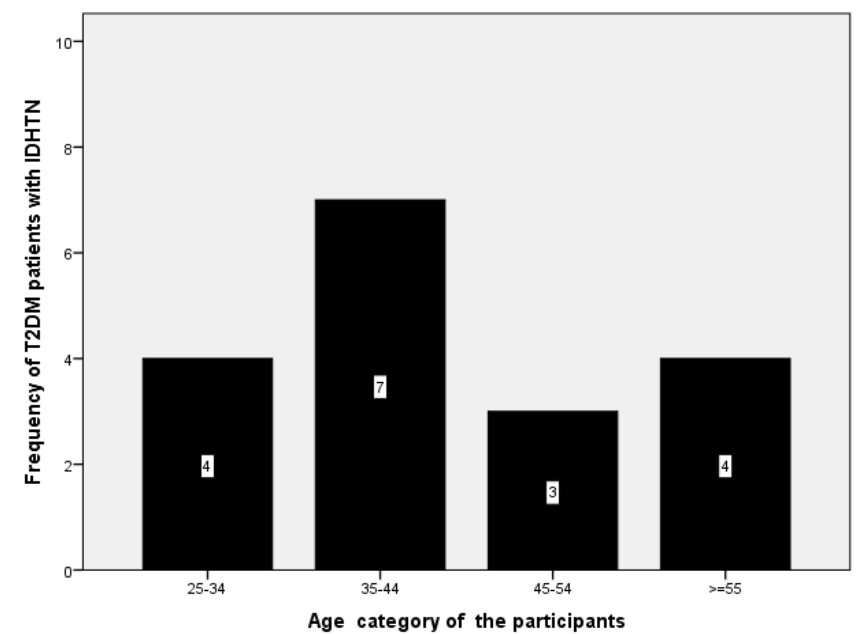

Figure 3: Shows ISHTN of the participants in age categories.

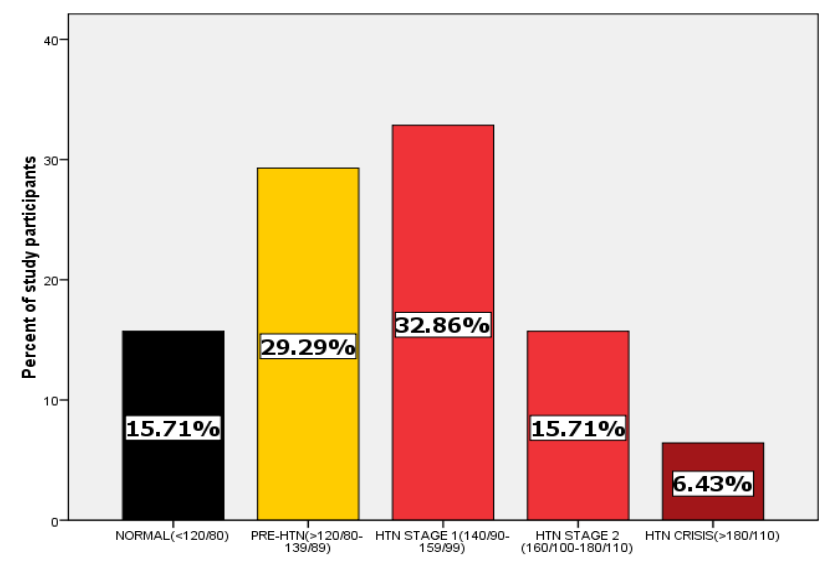

Figure 4: Blood pressure levels of study participants in Hosanna NEMM Hospital.

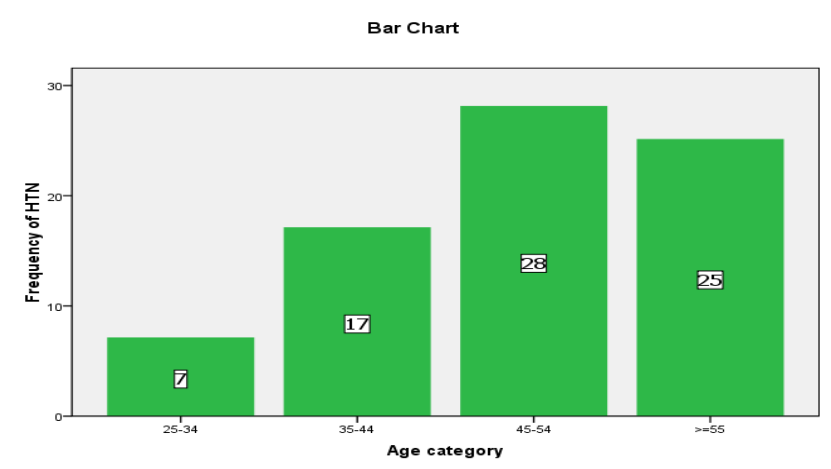

Figure 5: Prevalence of hypertension in age categories among T2DM patients in Hosanna NEMM Hospital.

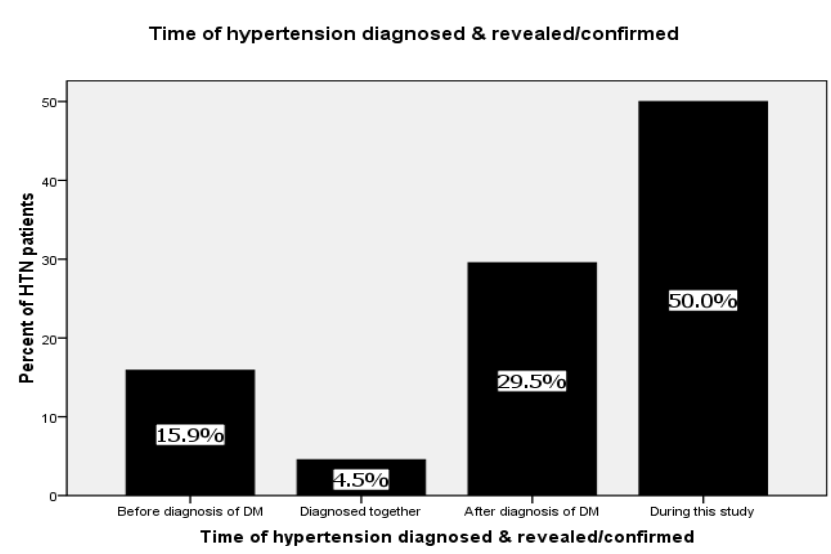

Figure 6: Shows prevalence rate of HTN based on the time it diagnosed and revealed/confirmed. 
Citation: Tadesse K, Amare H, Hailemariam T, Gebremariam T (2018) Prevalence of Hypertension among Patients with Type 2 Diabetes Mellitus and Its Socio Demographic Factors in Nigist Ellen Mohamed Memorial Hospital Hosanna, Southern Ethiopia. J Diabetes Metab 9: 792. doi: $10.4172 / 2155-6156.1000792$

Page 5 of 7

\begin{tabular}{|c|c|c|c|c|c|c|}
\hline \multicolumn{2}{|l|}{ Variables } & \multicolumn{3}{|c|}{ Hypertension } & \multirow{2}{*}{ AOR $[95 \% \mathrm{Cl}]$} & \multirow{2}{*}{ P-value } \\
\hline \multirow{5}{*}{ Age } & Categories & No & Yes & HTN\% $(\mathrm{N}=140)$ & & \\
\hline & 25-34(Ref.) & 14 & 7 & 5.00 & 1 & \\
\hline & $35-44$ & 18 & 17 & 12.14 & $2.287[1.478,10.936]$ & 0.022 \\
\hline & $45-54$ & 20 & 28 & 20.00 & $2.922[1.694,12.298]$ & 0.003 \\
\hline & $>=55$ & 11 & 25 & 17.86 & $6.396[1.221,33.496]$ & 0.000 \\
\hline \multirow{2}{*}{ Gender } & Female(Ref.) & 27 & 24 & 17.14 & 1 & \\
\hline & Male & 36 & 53 & 37.86 & $2.708[1.696,4.325]$ & 0.000 \\
\hline \multirow{4}{*}{ Marital status } & Unmarried(Ref.) & 2 & 5 & 3.58 & 1 & \\
\hline & Married & 56 & 70 & 50.00 & $15.167[1.935,246.129]$ & 0.000 \\
\hline & Divorced & 1 & 1 & 0.71 & $6.851[0.821,57.185]$ & 0.999 \\
\hline & Widowed & 4 & 1 & 0.71 & $1.015[0.0159,1.0159]$ & 0.657 \\
\hline \multirow{2}{*}{ Residence } & Urban & 31 & 40 & 28.57 & 1 & \\
\hline & Rural & 32 & 37 & 26.43 & $0.462[1.178,1.198]$ & 0.002 \\
\hline \multirow{7}{*}{ Occupation } & Government employee & 11 & 19 & 13.58 & 1 & \\
\hline & House wife & 16 & 14 & 10.00 & $0.643[0.211,1.873]$ & 0.418 \\
\hline & Self-employee & 9 & 10 & 7.14 & $0.589[0.178,1.956]$ & 0.388 \\
\hline & Farmers & 18 & 17 & 12.14 & $1.071[0.367,3.128]$ & 0.900 \\
\hline & Merchant & 2 & 5 & 3.57 & $2.571[0.269,24.554]$ & 0.412 \\
\hline & Retired & 2 & 7 & 5.00 & $3.429[0.372,31.589]$ & 0.277 \\
\hline & Others ${ }^{*}$ & 5 & 5 & 3.57 & $1.714[0.302,9.719]$ & 0.543 \\
\hline \multirow{7}{*}{ Educational status } & Illiterate & 14 & 20 & 14.28 & $1.494[0.405,5.510]$ & 0.546 \\
\hline & Writing and reading & 3 & 5 & 3.57 & $0.345[0.054,2.196]$ & 0.260 \\
\hline & 1 to 8 grade complete & 19 & 22 & 15.71 & $1.223[0.351,4.259]$ & 0.752 \\
\hline & Grade 9 to 10 complete & 4 & 6 & 4.18 & $1.846[0.313,10.886]$ & 0.498 \\
\hline & Grade 11 to 12 & 8 & 4 & 2.85 & $0.745[0.144,3.852]$ & 0.725 \\
\hline & College level certificate & 6 & 8 & 5.71 & $1.993[0.362,10.957]$ & 0.428 \\
\hline & First degree and above & 9 & 12 & 8.7 & 1 & \\
\hline \multirow{4}{*}{ Average Monthly income } & $<350$ Birr & 0 & 3 & 2.14 & $0.836[0.070,9.934]$ & 0.887 \\
\hline & 351-750 Birr & 5 & 7 & 5.00 & $0.374[0.068,2.046]$ & 0.257 \\
\hline & 751-1050 Birr & 4 & 7 & 5.00 & $0.852[0.200,3.639]$ & 0.829 \\
\hline & >1051 Birr & 54 & 60 & 42.86 & 1 & \\
\hline \multirow{2}{*}{ Average working Hours } & $\leq 8$ Hours & 27 & 49 & 35.00 & $0.394[0.178,0.870]$ & 0.000 \\
\hline & $>8$ Hours & 36 & 28 & 20.00 & 1 & \\
\hline
\end{tabular}

Table 2: Association of hypertension with Sociodemographic variables among T2DM Clients in Hosanna Nigist Ellen Mohammed Memorial Hospital.

HTN as compared to unmarried subjects; and being married is among independent predictors of HTN ( $\mathrm{p}$-value $=0.000$ ). Rural residents were $54 \%(\mathrm{AOR}=0.462,95 \% \mathrm{CI}: 1.178-1.198, \mathrm{P}=0.002)$ less likely to have $\mathrm{HTN}$ as compared to urban residents. Merchants were 2.6 times $[\mathrm{AOR}=2.571$, 95\%CI: $1.269-24.554]$ and retired were 3.43 times [AOR=2.571, 95\%CI: 1.372-31.589] more likely to have HTN as compared to government employee. Illiterates were 1.5times [AOR $=1.494,95 \% \mathrm{CI}: 1.405-5.510]$, grade 9-10 completes were 1.85 times [AOR $=1.846,95 \% \mathrm{CI}$ : 1.313 10.886] and college diploma graduates were about 2 times $[\mathrm{AOR}=1.993$, 95\%CI: 1.362-10.957] more likely to have HTN as compared to first degree and above graduates. From the total clients, $42.86 \%$ had HTN among those earning average monthly income greater than or equal to 1051 Ethiopian Birr.

\section{Discussion}

The result of this study shows that the prevalence of hypertension among patients with type 2DM clients attending chronic disease followup clinic in Hosanna NEMM hospital was $55 \%$ and $50 \%$ of them were newly revealed during this study period. From the study participants, $80.7 \%$ were achieved target $\mathrm{BP} \leq 130 / 80 \mathrm{mmHg}$ and $75 \%$ were achieved $\mathrm{BP} \leq 130 / 85 \mathrm{mmHg}$. The result of this study is almost consistent with the three cohort study conducted in Tel Aviv, Israel in 2005 on 2227 type 2 diabetic patients indicated that prevalence of HTN among the entire diabetic patients was $60.2 \%$. Hence, $76.5 \%$ and $85.8 \%$ of the entire study population had BP levels equal to or higher than 130/85 and 130/80 $\mathrm{mm} \mathrm{Hg}$, respectively. The prevalence of HTN clearly increased with age [19]. It is revealed by this study that half (50\%) out of the total HTN cases were confirmed during this study and this evidence indicates that HTN is still underdiagnosed among the other chronic diseases in this setting as elsewhere.

The prevalence rate of HTN in this study is low as compared with a prospective cohort study conducted in Iraqi from August 2008 to April 2011 on 5,578 patients with T2DM showed that hypertensive diabetic patients constituted $89.6 \%$ of this study subjects and $45.3 \%$ of them were newly discovered during the study period [20]; in German adults in 2009 was $73.5 \%$, but it was $40.80 \%$ in non-diabetic patients out of the total study subjects [21]; a cross-sectional study carried out in three Moroccan regions in 2011 on 525 T2DM patients was 70.4\% [22]; and a cross sectional study conducted in Botswana on the total of 401 T2DM subjects was $63.1 \%$ [23]. Prevalence rate of this study is higher than a cross-sectional comparative study conducted at Hawassa University Referral Hospital and Yirgalem Regional Hospital diabetic clinics in 2009 out of total 395 subjects was $23.1 \%$ [18]; a cross-sectional study conducted at Jimma University Specialized Hospital in 2007 out of 256 participants, $46.5 \%$ and $37.5 \%$ in 2012 [24,25]. The differences might be due to sociodemographic, study design, sample size variation and/ or awareness differences about the comorbidity of T2DM and HTN.

The results of the multivariate analyses shows that age is among the 
Citation: Tadesse K, Amare H, Hailemariam T, Gebremariam T (2018) Prevalence of Hypertension among Patients with Type 2 Diabetes Mellitus and Its Socio Demographic Factors in Nigist Ellen Mohamed Memorial Hospital Hosanna, Southern Ethiopia. J Diabetes Metab 9: 792. doi: $10.4172 / 2155-6156.1000792$

Page 6 of 7

factors independently associated with the HTN and prevalence of HTN clearly increased with age. It was highest $(20 \%)$ in the age group of $\geq 45$ years. This report is in line with the prospective cohort study conducted from August 2008 to April 2011 in Iraqi on 5,578 study participants showed independent association of older age (age $>50$ years) with the HTN and cross-sectional study carried out in Gaborone city, Botswana in 2004 revealed that older age (age $>50$ years) was associated with hypertension $[20,23]$.

In this finding, most of the participants were male (63.6\%), who were disproportionately represented by T2DM and male study subjects were 2.708 times more likely to have HTN as compared to females. These findings are consistent with evidence from a cross-sectional comparative study conducted in Sidama Zone Southern Ethiopia from October 2008 to February 2009 was 67.1\%; a case control study conducted in Tigray region, North Ethiopia, was 53.5\%, Punjab, India, 54\% [18,26,27]. But it is inconsistent with the report from Gaborone city, Botswana in 2004 and Pakistani in 2004 [23,28]. In this study, urban residents, merchants and illiterates were more likely to have HTN when compared with its counterpart, which is supported by the other large studies conducted in different countries (Ethiopia, Vietnam and Indonesia), Ghana, South Africa and Egypt as well [29-32]. Increasing urbanization is one of the main reasons for the rise of prevalence of hypertension in Africa. The levels of hypertension are structurally higher in urban than in rural settings [14]. This similarity might be mainly because of contextual and behavioural factors associated with urban environments such as dietary changes and sedentary lifestyle that together form a complex system conducive for developing hypertension. In this study average working hours per day was significantly associated with HTN and participants working their duty for $\leq 8 \mathrm{Hrs}$ /day were $60 \%$ less likely to have HTN as compared to those working their duties for $\geq 8 \mathrm{Hrs}$ /day. This fact might be related with work related stress and unsafe working environment.

\section{Conclusion}

T2DM and HTN are two of the most common diseases affecting large proportion of adults all over the world. Reliable information about the prevalence of hypertension in different world region is essential to the development of national and international health policies to prevent and control of burden of such comorbid conditions. Both are recognized as important risk factors for atherosclerosis, cardiovascular diseases including myocardial infarction and stroke. The two diseases often multiply the risk for complications if they coexist. More than half (55\%) of the type 2 diabetic clients in this study were hypertensive. The results conclude that there is a significant association between age, gender, marital status, residence of the clients and average working hours. Based on the findings of this study, the following recommendations were forwarded:

$\diamond \quad$ In addition to pharmacologic approach, comorbidity of HTN and T2DM can be reduced through health education.

$\diamond \quad$ Diabetic clinic should consider closer follow-up of patients for tight control of blood pressure for T2DM patients and home to home blood pressure screening program should be considered in health extension workers package.

$\diamond \quad$ In addition to government concern, prevention of Diabetes mellitus and hypertension need societal and community support. Therefore, health system policy makers should prioritize to prevent/ control coexistence of non-communicable chronic diseases in our case T2DM and HTN.

$\diamond \quad$ In order to address and monitor this epidemics, large prospective cohort study on prevalence of hypertension and related risk factors considering body mass index, waist circumference, salt intake, physical exercise, family history of HTN, serum cholesterol level, blood glucose level and drugs being taken other than T2DM and anti-HTN drugs, sleep apnea, stressful life style and other complications of T2DM recommended to be carried out.

\section{Ethical Approval and Consent to Participate}

Ethical clearance was obtained from Jimma University College of Health Sciences Institutional Research Review Board and oral consent from all study participants were obtained before conducting this study. Only code numbers but no names of the study participants were used at any stage of the study.

\section{Availability of Data and Materials}

The dataset used and/or analyzed during the current study available from the corresponding author on reasonable request.

\section{Competing Interests}

The authors declare that they have no competing interests in this section.

\section{Funding}

The expenses for this research work; data collectors, supervisors, data collectors' training, field work and stationary materials were supported by Jimma University and Dilla University.

\section{References}

1. WHO (2013) A global brief on hypertension. World Health Organization Press.

2. Katon WJ, Rutter C, Simon G, Lin EH, Ludman E, et al. (2005) The association of comorbid depression with mortality in patients with type 2 diabetes. Diabetes Care 28: 2668-2686.

3. Tunceli K, Bradley CJ, Nerenz D, Williams LK, Pladevall M, et al. (2005) The impact of diabetes on employment and work productivity. Diabetes Care 28: 2662-2668.

4. No authors (2013) Epidemiology of Hypertension. JAPI 61: 12-13.

5. Diabetes UK (2014) Diabetes facts and statistics. Care Connect Campaign.

6. Lim SS, Vos T, Flaxman AD, Danaei G, Shibuya K, et al. (2012) A comparative risk assessment of burden of disease and injury attributable to risk factors. Lancet 380: 2224-2242.

7. WHO (2008) Causes of death and global burden of disease.

8. Ueshima $\mathrm{H}$, Zhang $\mathrm{XH}$, Choudhury SR (2000) Epidemiology of hypertension in China and Japan. J Hum Hypertens 14: 765 -769.

9. Van de Vijver S, Akinyi H, Oti S, Olajide A, Agyemang C, et al. (2013) Status report on hypertension in Africa - Consultative review for the 6th Session of the African Union Conference of Ministers of Health on NCD's. Pan Afr Med J 16: 38.

10. Kaplan NM (2014) Hypertension in the population at large. Kaplan's Clinical Hypertension.

11. Mancia G1, Fagard R, Narkiewicz K, Redón J, Zanchetti A, et al. (2007) Guidelines for the management of arterial hypertension. The Task Force for the management of arterial hypertension of the European Society of Hypertension (ESH) and European Society of Cardiology (ESC). J Hypertens 31: 1281-1357.

12. Obimbo MM, Bundi PK, Collis F (2008) Foot complications among diabetics attending a district hospital in Kenya, predisposing factors and possible intervention. Ann Afr Surg 2: 338-348.

13. Otieno CF, Vaghela V, Mwendwa FW, Kayima JK, Ogola EN (2005) Cardiovascular risk factors in patients with type 2 diabetes mellitus in Kenya, levels of control attained at the outpatient diabetic clinic of Kenyatta National Hospital, Nairobi. East Afr Med J 83: 405-436.

14. Taylor BC, Timothy JW, Welch HG (2011) Impact of diastolic and systolic blood 
Citation: Tadesse K, Amare H, Hailemariam T, Gebremariam T (2018) Prevalence of Hypertension among Patients with Type 2 Diabetes Mellitus and Its Socio Demographic Factors in Nigist Ellen Mohamed Memorial Hospital Hosanna, Southern Ethiopia. J Diabetes Metab 9: 792. doi: 10.4172/2155-6156.1000792

Page 7 of 7

pressure on mortality implications for the definition of "normal". J Gen Intern Med 26: 11-46.

15. The Harvard School of Public Health (2012) Multidisciplinary International Research Training (HSPH MIRT) Program.

16. Kearney PM, Whelton M, Reynolds K, Muntner P, Whelton PK, et al. (2005) Global burden of hypertension: analysis of worldwide data. Lancet 365: 217-223.

17. No authors (2014) Hadiya Zone finance and development office report.

18. Giday A, Wolde M, Yihdego D (2010) Hypertension, obesity and central obesity in diabetics and non-diabetics in Southern Ethiopia. Ethiop J Health Dev 24

19. Kabakov E, Norymberg C, Osher E, Koffler M, Tordjman K, et al. (2006) Prevalence of hypertension in Type 2 Diabetes Mellitus: Impact of the tightening definition of high blood pressure and association with confounding risk factors. J Cardiometab Syndr 1: 95-101.

20. Mansour AA (2012) Prevalence and control of hypertension in Iraqi Diabetic Patients. Open Cardiovasc Med J 6: 68-71.

21. Reaven GM (1988) Banting lecture 1988. Role of insulin resistance in human disease1988. Diabetes 37: 1595-1607.

22. Berraho M, El Achhab Y, Benslimane A, El Rhazi K, Chikri M, et al. (2012) Hypertension and type 2 diabetes: a cross-sectional study in Morocco (EPIDIAM Study). Pan Afr Med J 11: 52.

23. Mengesha AY (2007) Hypertension and related risk factors in type 2 diabetes mellitus (DM) patients in Gaborone City Council (GCC) clinics, Gaborone, Botswana. Afr Health Sci 7: 244-245.
24. Gudina EK, Michael Y, Assegid S (2013) Prevalence of hypertension and its risk factors in southwest Ethiopia- a hospital-based cross-sectional survey. Integr Blood Press Control 6: 111-117.

25. Tamiru S, Alemseged F (2010) Risk factors for cardiovascular diseases among diabetic patients in Southwest Ethiopia. Ethiop J Health Sci 20: 121-128.

26. Giday TK, Behre AK (2014) Assessment of risk factors associated with type 2 diabetes mellitus in Central Zone of Tigrey, North Ethiopia. Int J Pharma Bio Sci Fundamentals 7: 20.

27. Kaur N, Sidhu S (2012) Prevalence of obesity and hypertension in newly diagnosed type 2 diabetes mellitus (T2dm) patients of Amritsar (Punjab), India. J Exer Sci Physiother 8: 6.

28. Arshad AR (2014) Control of blood pressure in hypertensive patients with diabetes mellitus type 2. Pak Heart J 47: 78-83.

29. Tesfaye F, Nawi NG, Van Minh H, Byass P, Berhane Y, et al. (2007) Association between body mass index and blood pressure across three populations in Africa and Asia. J Hum Hypertens 2: 28-37.

30. Agyemang C (2006) Rural and urban differences in blood pressure and hypertension in Ghana, West Africa. Public Health 120: 525-533.

31. Opie LH, Seedat YK (2005) Hypertension in sub-Saharan African populations. Circulation 112: 3562-3568.

32. Ibrahim MM (1996) The Egyptian National Hypertension Project (NHP) preliminary results. J Hum Hypertens 10: S39-S41. 